\title{
How to Define the Latent Reservoir: Tools of the Trade
}

\author{
Kirston M. Barton ${ }^{1} \cdot$ Sarah E. Palmer ${ }^{1}$ \\ Published online: 11 February 2016 \\ (C) The Author(s) 2016. This article is published with open access at Springerlink.com
}

\begin{abstract}
HIV is a devastating worldwide epidemic that has had substantial social and economic impacts throughout the globe. Due to the presence of a small pool of latently infected cells that persists during antiretroviral therapy (ART), HIV is not curable. Because of the high cost of ART and the lack of reliable accessibility across the globe, life-long ART is unfortunately not a feasible solution for the epidemic. Therefore, new strategies need to be developed and implemented to address HIV-1 infection. Several approaches toward this end are currently under investigation (Ebina et al. in Sci Rep 3:2510, 2013; Archin et al. in Nature 487:482-5, 2012; Elliott et al. in PLoS Pathog 10:e1004473, 2014; Rasmussen et al. in Lancet HIV 1:e13-e21, 2014; Tebas et al. in N Engl J Med 370:90110, 2014; Archin et al. in Nat Rev Microbiol 12:750-64, 2014; Barton et al. in PLoS One 9:e102684, 2014; Sogaard et al. in PLoS Pathog 11:e1005142, 2015). Initial studies have proven promising, but have highlighted the need for sensitive and accurate assays to detect changes in very low concentrations of virus to allow confident interpretation of the success of curative approaches. This review will focus on assays that are currently available and the advantages and limitations of each.
\end{abstract}

This article is part of the Topical Collection on HIV Pathogenesis and Treatment

Sarah E. Palmer

Sarah.Palmer@sydney.edu.au

Kirston M. Barton

Kirston.Barton@sydney.edu.au

1 Westmead Millennium Institute/University of Sydney, 176 Hawkesbury Road, Westmead, NSW 2145, Australia
Keywords Human immunodeficiency virus · Persistent HIV . Latent HIV · Viral outgrowth assay · Single-copy assay · HIV biomarkers $\cdot$ HIV pathogenesis $\cdot$ Review

\section{Introduction}

Antiretroviral therapy (ART) effectively reduces the amount of HIV-1 in infected individuals to levels that are undetectable by most clinical measures. However, the small reservoir of virus that is able to persist has the capacity to develop into a full HIV-1 infection if ART is stopped [1]. Therefore, this reservoir has important implications for infected individuals [2]. To cure HIV-1, gene therapy, bone marrow transplant, and combined pharmacological and immune therapy are some of the most well-known methods that are being actively explored. An accurate and sensitive measure of the latent reservoir is needed to measure outcomes of these studies $[3,4$, $5 \bullet \bullet, 6 \bullet \bullet, 7-9,10 \bullet \bullet$. The persistent reservoir of latent HIV-1 that remains during effective long-term therapy has been intensely studied, and several important features of the reservoir have been elucidated. The most well-studied reservoir exists in the resting CD4-positive T cells of the peripheral blood and in the intestine $[11,12]$. Most measures of the persistent pool of HIV-1 focus on the peripheral blood as a surrogate marker of other reservoirs due to its accessibility. However, alternate reservoirs of persistent HIV-1 have been detected in the lymph nodes, seminal fluid, and cerebral spinal fluid $[11,13]$. The majority of infected cells contain only a single HIV-1 integrant, meaning that measurement of integrated cellassociated DNA generally correlates with the number of cells that are infected with HIV $[14,15 \cdot \bullet]$. Once ART therapy is initiated, no viral evolution is detected indicating that there is no ongoing viral replication when ART adherence is high [16]. However, while HIV-1 does not replicate, the pool of 
latently infected cells can maintain or expand through cell proliferation of infected cells [17]. Therefore, while the persistent reservoir is not expanded through ongoing HIV-1 replication, due to the presence of long-lived cells and cell proliferation, it can be maintained over time. These important studies have paved the way for future assays to measure the latent reservoir and allow informed evaluation of the assays in use. To date, several innovative assays that measure various aspects of the latent reservoir have been developed, and these assays are being used to direct clinical decisions regarding continuation of ART.

To fully understand the difficulty of developing an effective and efficient measure of the latent reservoir, it is important to define what an ideal assay would include. The first and most important feature, but possibly the most difficult, would be to measure the entire reservoir of replication competent virus and nothing more. Specifically, the assay would need to quantify replication competent HIV-1 without including defective virus. The majority of HIV-1 proviral genomes that persist in HIV-1-infected individuals on long-term suppressive therapy are defective in that they contain premature stop codons and/or large internal deletions and insertions [18•]. It is important to distinguish between defective and replication competent virus because in theory, HIV-1-infected individuals could remain off ART indefinitely if all replication competent viruses are eliminated while cells containing defective virus remain. However, defective virus that is not replication competent, but makes partial viral proteins, can cause persistent immune activation. Persistent immune activation also has long-term deleterious effects, and therefore, sterilizing strategies that remove all HIV-1, such as gene therapy, may ultimately prove to be an optimal therapeutic choice.

Second, an ideal assay would be able to provide an accurate assessment of how much replication competent virus is present in tissue compartments that are not necessarily sampled. Due to the limited amount of interventions a participant can reasonably be expected to endure to efficiently deploy an assay across the many health-care systems around the globe, an ideal assay would require only a single blood sample, but would need to be able to accurately predict the levels of HIV-1 in tissue compartments such as the intestine, the lymph nodes, the nervous system, and yet undefined populations. Third, an ideal assay would have very strong confidence in a negative result as false negatives would have devastating effects on the patient. While this may seem like a difficult task at first glance, combining current methods with theoretical modeling may provide sufficient data to make initial predictions while more sensitive and deployable methods are developed.

\section{Assays to Measure the Persistent Reservoir}

The first group of assays that is going to be discussed measures virus that is replication competent and can infect cells in culture. Collectively, these assays use viral outgrowth to measure the latent reservoir. So far, three assays have been developed. As a group, viral outgrowth assays are very promising because they are the only class of assays that detect only replication competent virus. However, they share a common limitation in that they are not necessarily able to detect all replication competent viruses and, if used as the sole predictor of reservoir size could, lead to premature discontinuation of ART [18•].

The quantitative viral outgrowth assay (QVOA) is currently the gold standard for detection of the HIV-1 latent reservoir $[1,19,20]$. In this assay, blood or leukopheresis product is obtained from HIV-1-infected individuals, and CD4+ T cells are isolated by negative selection. The CD4+ T cells are plated in limiting dilution to allow quantification and are stimulated with PHA and irradiated lymphoblasts from a non-infected donor to induce viral outgrowth. Then, CD8+ depleted lymphoblasts are added to amplify the virus that is released. After several weeks of incubation, the wells that contained replication competent HIV-1 are detected by ELISA for HIV-1 p24 antigen. QVOA has many advantages with the most pronounced being its ability to only detect replication competent virus. However, it is also costly, time-consuming, and resource-intensive; requires large samples from the study participants; and does not detect all replication competent virus $[18 \bullet, 21]$. Several variants of this assay have been developed to reduce the cost and length of QVOA including the use of MOLT-4/CCR5 cells in place of donor cells for viral expansion, which decreases the amount of required culture time [22]. This assay also reduces the total time by detecting HIV-1 RNA with quantitative PCR (qPCR) instead of using ELISA. The initial steps of the viral outgrowth assay are followed; however, culturing is stopped after only three or seven days, and viral RNA is detected by qPCR [22].

An alternative to the traditional QVOA was recently proposed by Swanstrom et al. in which the maximum number of CD4+ T cells (ten million) is cultured in each well, and then, the positive wells are sequenced using ultra-deep sequencing to determine the number of unique viruses that replicated in each well. This approach allows more cells to be cultured with fewer resources. One minor limitation to this assay is that it is less accurate in participants treated during acute infection due to a lack of genetic diversity, which is necessary to be able to quantitate the number of individual founder viruses were present in each well [23].

Recently, another variant of the viral outgrowth assay using humanized mice (MVOA) was developed. In this assay, $\mathrm{CD}^{+}$ $\mathrm{T}$ cells or PBMCs from HIV-infected individuals are injected into Nod.CgPrkdc ${ }^{\text {scid }}$ IL $2 \mathrm{rg}^{\mathrm{Tm} 1 \mathrm{Wj} 1} / \mathrm{SzJ}$ (NSG) mice. Viral loads are then monitored using real-time PCR for HIV1 RNA. Up to 60 million cells can be injected per mouse, and multiple mice can be used per HIV-1-infected individual increasing the number of cells that can be screened. In the trials that have been run so far, HIV-1 was detected in mice injected with cells from participants on ART and elite controllers with viral loads less 
than 50 copies per milliliter. HIV-1 RNA was detected in the plasma of the humanized mice after xenograft with PBMCs from five participants who were on effective long-term ART and from six elite controllers. MVOA also has the potential to screen cells from alternate tissue reservoirs such as the gutassociated lymphoid tissue and lymph nodes. This assay has a higher sensitivity than the QVOA but is not quantitative and is thus limited to determining whether the participant still harbors replication competent virus [24]. MVOA is a very powerful tool for determining whether replication competent virus is present in large amounts of cells. However, the MVOA assay would be less informative in detecting fold reductions in the latent reservoir that could potentially lead to long periods of HIV-1 remission.

Residual viremia can be detected in a significant portion of HIV-1-infected individuals on effective therapy using very sensitive methods $[25,26]$. The single-copy assay (SCA) is a sensitive real-time RT-PCR-based assay that can measure down to one copy of viral RNA per milliliter of plasma [25-29]. SCA uses primers directed at the highly conserved regions of gag and integrase. Comparison to serial dilutions of a standard is used to quantify the total amount of viral RNA. In addition, an internal standard (avian retrovirus) is added to all plasma samples to monitor the extraction and measurement of low-level viral RNA. SCA is more sensitive than any of the clinical detection methods that are currently available. Commercial assays including the Roche Ampliprep [30] and Abbot real time HIV-1 assays can also be used to measure HIV-1 RNA in the plasma. These assays are much less sensitive than the SCA with lower limits of 20 or 40 copies per milliliter, respectively. Assays that measure plasma RNA do not detect latent virus that is not producing transcripts and do not determine whether the virus is replication competent. Furthermore, because they use specific primers, some proportion of virus may not be detected due to mutation or viral variation. Despite these limitations, the single-copy assay can often detect plasma RNA in individuals on ART.

During the HIV-1 replication cycle, several nucleic acid forms of the viral genome are created including full-length viral RNA, 2-LTR DNA circles, integrated DNA, as well as multiply spliced and incompletely spliced mRNA. Quantitative PCR assays can be used to distinguish between each form or to measure total RNA or DNA according to the amplification region [31]. It is important to carefully select which region is targeted by these assays. Short abortive transcripts from the HIV-1 LTR can be detected in the absence of full transcription due to limitations of the elongation machinery [32]. Additionally, regions such as env are known to be highly diverse, which makes false negatives due to primer mismatch more likely. Protein regions such as tat and integrase are highly conserved and are therefore less likely to produce false negative results. When measuring RNA, it is important to keep in mind that fully spliced RNAs are produced early in infection and encode rev, which is required for nuclear export and translation of multiply spliced and unspliced HIV-1 RNA. Furthermore, HIV-1 integrated into an exon of a gene can be translated as a full-length genome within that gene without the potential to be translated into functional proteins or be incorporated into a virion as a viral genome [2, 11]. Additionally, integrated DNA species that contain mutations rendering them defective may still produce RNAs. Defective integrated HIV-1 genomes can be propagated through cellular proliferation due to antigenic or homeostatic proliferation. Multiply spliced RNAs are highly expressed during early infection peaking at five hours while unspliced RNAs dominate at later stages of infection [33]. Furthermore, multi-spliced RNAs are generally undetectable in individuals on ART while unspliced RNA can be detected at a very low level [32]. A ratio of the two species can be used to provide an idea of whether new infections are occurring $[32,34,35]$. Therefore, detection of each type of viral RNA or DNA provides an independent measure with varying amounts of reliability regarding its ability to predict how much replication competent HIV-1 is present $[18 \bullet, 36]$.

The PCR-based assays are the most flexible group of assays available in that they are able to differentiate between many different stages of the viral life cycle [11,37-41]. Additionally, these assays are very sensitive and specific. Most assays in use rely on quantitative real-time PCR, while some of the newer methods have moved to digital droplet PCR (ddPCR) to increase sensitivity [42]. Measurement of total DNA includes both integrated and 2-LTR circle forms of the HIV-1 genome $[43,44]$. While the longevity of 2-LTR circles is controversial, accurate measures of integrated HIV-1 genomes can be measured using Alu PCR [29, 45-47]. Alu PCR is a method that takes advantage of very common $A l u$ elements that are present in the human genome along with HIV-1-specific primers that bind to the gag region. Together, these primer sets are used to detect integrated HIV-1 DNA in cells [48-50].

The tat/rev induced limiting dilution assay (TILDA) measures inducible multiply spliced HIV-1 RNA [51]. This approach is a better predictor of the actual reservoir size than other PCR-based methods because it measures RNAs produced in response to stimulation with PMA indicating that the proviral LTR is intact. Furthermore, the primers used for TILDA are specific to the tat/rev region, which is the most commonly deleted region in proviruses. In one study, TILDA predicted a latent reservoir that was 48 times higher than that predicted by QVOA and 6-27 times lower than that predicted by PCR-based assays, supporting its ability to measure a larger proportion of the latent reservoir than QVOA while being more discriminating than traditional PCR-based approaches [51].

While highly sensitive, none of the PCR-based assays are able to fully differentiate between replication competent and defective virus, meaning that for the most part, they may over estimate the total latent reservoir. Additionally, due to the 
capricious nature of the HIV-1 genome, even primers targeting the most conserved regions may miss some sequences. Moreover, many of the primers used for PCR assays are somewhat subtype-specific, and therefore, knowledge of the subtype may be required for optimal implementation. Despite these drawbacks, PCR-based assays are some of the least expensive and most transferable assays available. Furthermore, PCR assays may be able to be combined with sequencing data to estimate the percent of detected HIV that is defective and provide a more accurate measure of the latent reservoir.

Measures of the immune response can also be used as biomarkers to predict HIV-1-free remission. Several different measures of immune activity are available including HIV-1 antibody detection, response of T cells to HIV-1 antigen, and markers of activated T cells. To measure HIV-1-specific antibodies, the most common method in use is ELISA. ELISA can detect both the avidity and quantity of HIV-1 antibodies and can be used to predict whether the participant is acutely or chronically infected with HIV [52]. Two recent studies following participants with stem cell transplants both showed declines in HIV-1 antibodies over time [53••, 54••]. However, this decline is associated with a continued remission for one individual while it was only associated with a delay in viral rebound for the other two individuals. Therefore, while the levels and avidity of HIV-1 antibodies can be used as a predictor of HIV-1 levels, this method may need to be supplemented with additional measures. The luciferase immunoprecipitation system, which uses chimeric Renilla luciferase and pathogen-specific antigens to quantitate HIV-1-specific antibodies, demonstrated that the levels of antibodies to p24 and gp41 were significantly lower in a participant that has not rebounded than in elite controllers who control viremia without ART and HIV-infected individuals on or not on ART. Therefore, the levels of p24- and gp41-specific antibodies may be a surrogate biomarker of reservoir size [55].

$\mathrm{HIV}$-specific T cell responses can also be used as a measure of recent exposure of the immune system to viral proteins. In this assay, total PBMCs are exposed to HIV-1 peptides and intramolecular staining for known cytokines is used to determine whether CD4 and CD8 T cells are responsive to HIV. A decline of T cell specificity for HIV-1 peptides indicates that the immune system has not been exposed to antigen recently. However, a recent study by Oleson et al. found that in their study group, cytokine expression was not correlated with levels of HIV DNA; however, they did find that the frequency of natural killer cells was inversely correlated with levels of HIV DNA in infected individuals [56]. In addition to the response of T cells, cell surface proteins that correlate with cell activation are biomarkers that may be useful to predict reservoir size. Levels of HIV-1 proviral DNA are significantly correlated with markers of cell activation with the strongest association being observed between HIV-1 proviral DNA and the markers PD-1 and HLA-DR $[57,58]$. Therefore, PD-1 and
HLA-DR expression could also potentially be used as a alternate markers for the presence of residual HIV-1.

One common feature of all the assays that have been discussed above is that they all are largely used and optimized in peripheral blood samples. However, the lymph node and gut-associated lymph node tissues are also well-known reservoirs of persistent HIV. As stated above, an ideal assay would use a small blood sample and provide a prediction of the total pool of persistent HIV. However, to determine whether an assay is a good predictor of the total reservoir, it is important to have a thorough understanding of how much persistent HIV is in each tissue reservoir. RNA/DNAscope (NAscope) was developed by Jacob Estes to detect HIV-1 RNA and DNA in tissue specimens [59]. NAScope is a modified version of traditional in-situ hybridization that is more specific allowing individually infected cells to be detected and quantitated. The PCR-based methods discussed above as well as traditional in-situ hybridization techniques have also been used to detect HIV-1 in tissue samples [54••, 60-63]. Sequencing can also be used to characterize persistent reservoirs in tissue samples and compare them to the peripheral blood components. Sequencing studies of the lymph nodes and gutassociated lymph node tissues have largely showed that these populations intermingle with HIV populations from the peripheral blood indicating that HIV-1 regularly traffics between these compartments [16]. Analysis of the cerebral spinal fluid in some individuals does indicate that compartmentalization can occur across the blood brain barrier [64]. As new curative strategies progress from the initial phases, it will be crucial that the reservoirs in the tissue compartment be quantifiable so that the effects of new strategies can be measured.

ART treatment interruption is the ultimate measure of whether replication competent virus persists. Many have reservations about using treatment interruption as lack of ART adherence and treatment interruptions has been shown to correlate with poorer health outcomes for the patients $[65,66]$. However, these studies were not designed to closely monitor participants and place them back on ART as is proposed for the analytical treatment interruptions to test the efficacy of curative/remission strategies. Additional studies need to be conducted to determine the full effects of well-controlled analytical treatment interruptions and whether the participants are significantly negatively affected.

A functional cure in which all replication competent virus is eliminated is the ultimate goal of HIV-1 research. However, recent studies have indicated that decreasing the HIV-1 reservoir by several folds may be sufficient to effect HIV-1 remission during which HIV-1 infected individuals could stop taking therapy for months or years without recurrent viremia. The Davenport lab analyzed the results from four cohorts and a total of 100 participants who underwent treatment interruption and determined that on average, a new virus reactivates 
Fig. 1 The many different stages of the HIV replication cycle and the response of the host's immune system can be detected with sensitive assays to quantitate HIV in HIV-infected individuals on effective long-term antiretroviral therapy

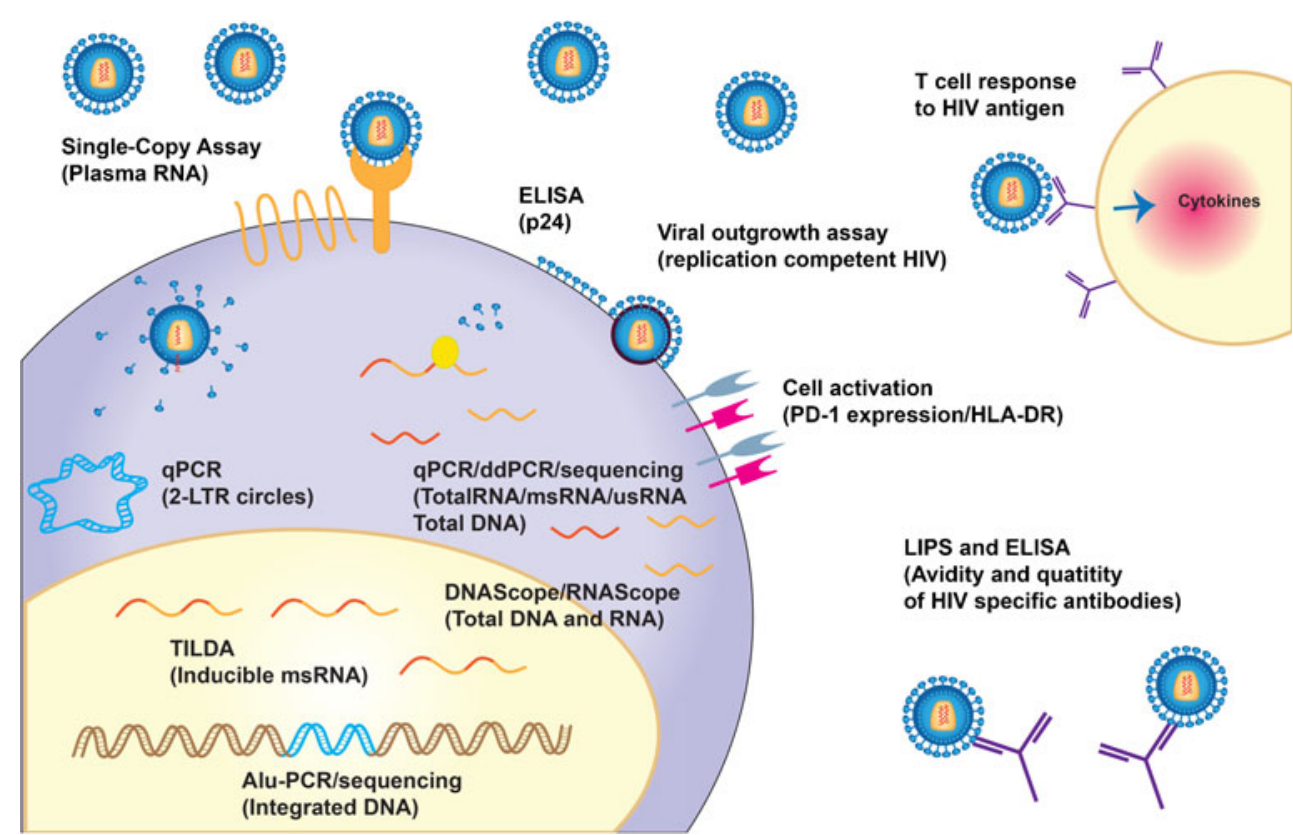

every five to eight days [67•]. Furthermore, based on this number, they estimate that a 50-70-fold reduction in the viral reservoir would be needed to achieve HIV-1 remission for approximately one year, which is less than the 2000-fold reduction that was previously estimated $[67 \bullet, 68]$. Most of the assays that are currently being used to estimate the latent reservoir are close to the limit of detection with the current levels of persistent HIV-1 in participants on long-term effective therapy. To be able to detect a 50-70-fold reduction in these levels, significantly more sensitive assays and technologies will need to be developed.

Eriksson et al. compared some of the most common assays that are used to measure the latent reservoir including qPCR and ddPCR for HIV-1 DNA, Alu PCR for integrated HIV-1 DNA, DNA and RNA in the gutassociated lymphoid tissue, ddPCR for 2-LTR circles, and the single-copy assay, and compared them to results from the same study participants using the viral outgrowth assay [69••]. None of the measurements from the techniques studied were strongly correlated with the results from the viral outgrowth assay, which is not surprising given that each assay measures very different aspects of HIV-1 replication that may expand or contract independently (Fig. 1). Additionally, Chun et al. compared HIV-1 DNA to plasma viremia and markers of immune activation and found a correlation between plasma viremia and cell-associated DNA, but did not observe a significant correlation when they compared cellassociated DNA to markers of immune activation [41]. These studies highlight the fact that with the currently available technologies, the results from multiple methods may need to be combined to predict a confident estimate of the size of the reservoir.

In addition to these studies, a large collaboration between several different labs using most of the current techniques available with a large range of anatomical samples attempted to detect HIV-1 in the longest case of HIV-1 remission currently known as the Berlin patient [54••]. HIV-1 RNA/DNA was detected at very low levels in three independent labs; however, to date, no viral rebound has occurred. In contrast, a similar study was performed on two participants who received bone marrow transplants in which no virus was detected by any of the methods used. However, both of these individuals experienced rebound following treatment interruption $[53 \bullet \bullet$. These two studies highlight the difficulty of accurately measuring the latent reservoir.

\section{Conclusions}

In conclusion, many innovative and sensitive assays are available to measure and predict the size of the persistent reservoir in HIV-1-infected individuals on long-term suppressive therapy. Despite some limitations for each assay, combining these techniques may provide a powerful estimation of the latent reservoir. A clear understanding of each assay and how to interpret the information provided is critical for translating the findings into meaningful recommendations for patients. Even with the best and most careful measurements, it is likely that well-monitored analytical treatment interruptions will provide the most significant insights into the effectiveness of cure and remission studies. 
Acknowledgments This work was primarily supported by the amfAR Research Consortium on HIV Eradication (ARCHE) (107857-48RGRL), (108074-50-RGRL), The Foundation for AIDS Research (108021-49-RFRL), the Delaney AIDS Research Enterprise (U19 AI096109), and the Australian National Health and Medical Research Council (AAP1061681)

\section{Compliance with Ethical Standards}

Conflict of Interest The authors declare that they have no competing interests.

Human and Animal Rights and Informed Consent This article does not contain any studies with human or animal subjects performed by any of the authors.

Open Access This article is distributed under the terms of the Creative Commons Attribution 4.0 International License (http:// creativecommons.org/licenses/by/4.0/), which permits unrestricted use, distribution, and reproduction in any medium, provided you give appropriate credit to the original author(s) and the source, provide a link to the Creative Commons license, and indicate if changes were made.

\section{References}

Papers of particular interest, published recently, have been highlighted as:

- Of importance

•- Of major importance

1. Finzi D, Blankson J, Siliciano JD, Margolick JB, Chadwick K, Pierson T, et al. Latent infection of CD4+ T cells provides a mechanism for lifelong persistence of HIV-1, even in patients on effective combination therapy. Nat Med. 1999;5(5):512-7. doi:10.1038/ 8394.

2. McMahon JH, Elliott JH, Roney J, Hagenauer M, Lewin SR. Experiences and expectations of participants completing an HIV cure focused clinical trial. Aids. 2015;29(2):248-50. doi:10.1097/ QAD.0000000000000534.

3. Ebina H, Misawa N, Kanemura Y, Koyanagi Y. Harnessing the CRISPR/Cas9 system to disrupt latent HIV-1 provirus. Sci Rep. 2013;3:2510. doi:10.1038/srep02510.

4. Archin NM, Liberty AL, Kashuba AD, Choudhary SK, Kuruc JD, Crooks AM, et al. Administration of vorinostat disrupts HIV-1 latency in patients on antiretroviral therapy. Nature. 2012;487(7408): 482-5. doi:10.1038/nature11286.

5.• Elliott JH, Wightman F, Solomon A, Ghneim K, Ahlers J, Cameron MJ, et al. Activation of HIV transcription with short-course vorinostat in HIV-infected patients on suppressive antiretroviral therapy. PLoS Pathog. 2014;10(10):e1004473. doi:10.1371/journal.ppat.1004473. First clinical trial conducted using vorinostat that showed viral reactivation following administration.

6.• Rasmussen TA, Tolstrup M, Brinkmann CR, Olesen R, Erikstrup C, Solomon A, et al. Panobinostat, a histone deacetylase inhibitor, for latent-virus reactivation in HIV-infected patients on suppressive antiretroviral therapy: a phase $1 / 2$, single group, clinical trial. Lancet HIV. 2014;1(1):e13-21. doi:10.1016/S2352-3018(14)70014-1. This clinical trial demonstrates that panobinostat activates HIV-1 transcription in vivo.
7. Tebas P, Stein D, Tang WW, Frank I, Wang SQ, Lee G, et al. Gene editing of CCR5 in autologous CD4 T cells of persons infected with HIV. New England J Med. 2014;370(10):901-10. doi:10.1056/ NEJMoa1300662.

8. Archin NM, Sung JM, Garrido C, Soriano-Sarabia N, Margolis DM. Eradicating HIV-1 infection: seeking to clear a persistent pathogen. Nat Rev Microbiol. 2014;12(11):750-64. doi:10.1038/ nrmicro3352.

9. Barton KM, Archin NM, Keedy KS, Espeseth AS, Zhang YL, Gale J, et al. Selective HDAC inhibition for the disruption of latent HIV1 infection. PLoS One. 2014;9(8), e102684. doi:10.1371/journal. pone. 0102684 .

10.• Sogaard OS, Graversen ME, Leth S, Olesen R, Brinkmann CR, Nissen SK, et al. The depsipeptide romidepsin reverses HIV-1 latency in vivo. PLoS Pathog. 2015;11(9):e1005142. doi:10.1371/ journal.ppat.1005142. A recent clinical trial demonstrating that romidepsin reactivates HIV from latency in vivo.

11. Chun TW, Finzi D, Margolick J, Chadwick K, Schwartz D, Siliciano RF. In vivo fate of HIV-1-infected T cells: quantitative analysis of the transition to stable latency. Nat Med. 1995;1(12): 1284-90.

12. Soriano-Sarabia N, Bateson RE, Dahl NP, Crooks AM, Kuruc JD, Margolis DM, et al. Quantitation of replication-competent HIV-1 in populations of resting CD4+ T cells. J Virol. 2014;88(24):14070-7. doi:10.1128/JVI.01900-14.

13. Nottet HS, van Dijk SJ, Fanoy EB, Goedegebuure IW, de Jong D, Vrisekoop N, et al. HIV-1 can persist in aged memory CD4+ T lymphocytes with minimal signs of evolution after 8.3 years of effective highly active antiretroviral therapy. J Acquir Immune Defic Syndr. 2009;50(4):345-53. doi:10.1097/QAI. 0b013e318197eb04.

14. Josefsson L, King MS, Makitalo B, Brannstrom J, Shao W, Maldarelli F, et al. Majority of CD4+ T cells from peripheral blood of HIV-1-infected individuals contain only one HIV DNA molecule. Proc Natl Acad Sci U S A. 2011;108(27):11199-204. doi:10. 1073/pnas.1107729108.

15.• Josefsson L, Palmer S, Faria NR, Lemey P, Casazza J, Ambrozak D, et al. Single cell analysis of lymph node tissue from HIV-1 infected patients reveals that the majority of CD4+ T-cells contain one HIV-1 DNA molecule. PLoS Pathog. 2013;9(6):e1003432. doi:10.1371/ journal.ppat. 1003432 . Important work conclusively demonstrating that each HIV-infected cell generally contains a single integrated HIV-1 genome.

16. Josefsson L, von Stockenstrom S, Faria NR, Sinclair E, Bacchetti P, Killian M, et al. The HIV-1 reservoir in eight patients on long-term suppressive antiretroviral therapy is stable with few genetic changes over time. Proc Natl Acad Sci U S A. 2013;110(51):E4987-96. doi: 10.1073/pnas. 1308313110 .

17. von Stockenstrom S, Odevall L, Lee E, Sinclair E, Bacchetti P, Killian M, et al. Longitudinal genetic characterization reveals that cell proliferation maintains a persistent HIV type 1 DNA pool during effective HIV therapy. J Infect Dis. 2015. doi:10.1093/infdis/ jiv092.

18. Ho YC, Shan L, Hosmane NN, Wang J, Laskey SB, Rosenbloom DI, et al. Replication-competent noninduced proviruses in the latent reservoir increase barrier to HIV-1 cure. Cell. 2013;155(3):540-51. doi:10.1016/j.cell.2013.09.020. A thorough study demonstrating that the majority of detectable HIV RNA and DNA in individuals on ART is defective.

19. Finzi D, Hermankova M, Pierson T, Carruth LM, Buck C, Chaisson $\mathrm{RE}$, et al. Identification of a reservoir for HIV-1 in patients on highly active antiretroviral therapy. Science. 1997;278(5341): 1295-300.

20. Crooks AM, Bateson R, Cope AB, Dahl NP, Griggs MK, Kuruc JD, et al. Precise quantitation of the latent HIV-1 reservoir: implications 
for eradication strategies. J Infect Dis. 2015. doi:10.1093/infdis/ jiv218.

21. Siliciano JD, Siliciano RF. Enhanced culture assay for detection and quantitation of latently infected, resting CD4+ T-cells carrying replication-competent virus in HIV-1-infected individuals. Methods Mol Biol. 2005;304:3-15. doi:10.1385/1-59259-9079:003.

22. Laird GM, Eisele EE, Rabi SA, Lai J, Chioma S, Blankson JN, et al. Rapid quantification of the latent reservoir for HIV-1 using a viral outgrowth assay. PLoS Pathog. 2013;9(5), e1003398. doi:10.1371/ journal.ppat. 1003398.

23. Lee SKZ S, Archin N, Margolis D, Swanstrom R. Assay to measure replication-competent HIV-1 in supressed patients based on ultradeep sequencing, IAS. Canada: Vancouver; 2015.

24. Metcalf Pate KA, Pohlmeyer CW, Walker-Sperling VE, Foote JB, Najarro KM, Cryer CG, et al. A murine viral outgrowth assay to detect residual HIV type 1 in patients with undetectable viral loads. J Infect Dis. 2015. doi:10.1093/infdis/jiv230.

25. Palmer S, Maldarelli F, Wiegand A, Bernstein B, Hanna GJ, Brun $\mathrm{SC}$, et al. Low-level viremia persists for at least 7 years in patients on suppressive antiretroviral therapy. Proc Natl Acad Sci U S A. 2008;105(10):3879-84. doi:10.1073/pnas.0800050105.

26. Maldarelli F, Palmer S, King MS, Wiegand A, Polis MA, Mican J, et al. ART suppresses plasma HIV-1 RNA to a stable set point predicted by pretherapy viremia. PLoS Pathog. 2007;3(4), e46. doi:10.1371/journal.ppat.0030046.

27. Palmer S, Wiegand AP, Maldarelli F, Bazmi H, Mican JM, Polis M, et al. New real-time reverse transcriptase-initiated PCR assay with single-copy sensitivity for human immunodeficiency virus type 1 RNA in plasma. J Clin Microbiol. 2003;41(10):4531-6.

28. Cillo AR, Vagratian D, Bedison MA, Anderson EM, Kearney MF, Fyne E, et al. Improved single-copy assays for quantification of persistent HIV-1 viremia in patients on suppressive antiretroviral therapy. J Clin Microbiol. 2014;52(11):3944-51. doi:10.1128/ JCM.02060-14.

29. Markowitz M, Evering TH, Garmon D, Caskey M, La Mar M, Rodriguez K, et al. A randomized open-label study of 3- versus 5-drug combination antiretroviral therapy in newly HIV-1infected individuals. J Acquir Immune Defic Syndr. 2014;66(2): 140-7. doi:10.1097/QAI.0000000000000111.

30. De Bel A, Marissens D, Debaisieux L, Liesnard C, Van den Wijngaert S, Lauwers S, et al. Correction of underquantification of human immunodeficiency virus type 1 load with the second version of the Roche Cobas AmpliPrep/Cobas TaqMan assay. J Clin Microbiol. 2010;48(4):1337-42. doi:10.1128/JCM.01226-09.

31. Hatano H, Delwart EL, Norris PJ, Lee TH, Dunn-Williams J, Hunt $\mathrm{PW}$, et al. Evidence for persistent low-level viremia in individuals who control human immunodeficiency virus in the absence of antiretroviral therapy. J Virol. 2009;83(1):329-35. doi:10.1128/JVI. 01763-08.

32. Lassen KG, Bailey JR, Siliciano RF. Analysis of human immunodeficiency virus type 1 transcriptional elongation in resting CD4+ T cells in vivo. J Virol. 2004;78(17):9105-14. doi:10.1128/JVI.78.17. 9105-9114.2004.

33. Bagnarelli P, Valenza A, Menzo S, Sampaolesi R, Varaldo PE, Butini L, et al. Dynamics and modulation of human immunodeficiency virus type 1 transcripts in vitro and in vivo. J Virol. 1996;70(11):7603-13.

34. Hermankova M, Siliciano JD, Zhou Y, Monie D, Chadwick K, Margolick JB, et al. Analysis of human immunodeficiency virus type 1 gene expression in latently infected resting CD4+ T lymphocytes in vivo. J Virol. 2003;77(13):7383-92.

35. Vesanen M, Markowitz M, Cao Y, Ho DD, Saksela K. Human immunodeficiency virus type-1 mRNA splicing pattern in infected persons is determined by the proportion of newly infected cells. Virology. 1997;236(1):104-9. doi:10.1006/viro.1997.8718.
36. Besson GJ, Lalama CM, Bosch RJ, Gandhi RT, Bedison MA, Aga E, et al. HIV-1 DNA decay dynamics in blood during more than a decade of suppressive antiretroviral therapy. Clin Infect Dis. 2014;59(9):1312-21. doi:10.1093/cid/ciu585.

37. Besson GJ, McMahon D, Maldarelli F, Mellors JW. Short-course raltegravir intensification does not increase 2 long terminal repeat episomal HIV-1 DNA in patients on effective antiretroviral therapy. Clin Infect Dis : Off Publ Infect Dis Soc Am. 2012;54(3):451-3. doi:10.1093/cid/cir721.

38. Zhu W, Jiao Y, Lei R, Hua W, Wang R, Ji Y, et al. Rapid turnover of 2-LTR HIV-1 DNA during early stage of highly active antiretroviral therapy. PLoS One. 2011;6(6), e21081. doi:10.1371/journal.pone. 0021081.

39. Gandhi RT, Coombs RW, Chan ES, Bosch RJ, Zheng L, Margolis $\mathrm{DM}$, et al. No effect of raltegravir intensification on viral replication markers in the blood of HIV-1-infected patients receiving antiretroviral therapy. J Acquir Immune Defic Syndr. 2012;59(3):229-35. doi:10.1097/QAI.0b013e31823fd1f2.

40. Cillo AR, Krishnan A, Mitsuyasu RT, McMahon DK, Li S, Rossi JJ, et al. Plasma viremia and cellular HIV-1 DNA persist despite autologous hematopoietic stem cell transplantation for HIV-related lymphoma. J Acquir Immune Defic Syndr. 2013;63(4):438-41. doi:10.1097/QAI.0b013e31828e6163.

41. Chun TW, Murray D, Justement JS, Hallahan CW, Moir S, Kovacs $\mathrm{C}$, et al. Relationship between residual plasma viremia and the size of HIV proviral DNA reservoirs in infected individuals receiving effective antiretroviral therapy. J Infect Dis. 2011;204(1):135-8. doi:10.1093/infdis/jir208.

42. Strain MC, Lada SM, Luong T, Rought SE, Gianella S, Terry VH, et al. Highly precise measurement of HIV DNA by droplet digital PCR. PLoS One. 2013;8(4), e55943. doi:10.1371/journal.pone. 0055943.

43. Rouzioux C, Melard A, Avettand-Fenoel V. Quantification of total HIV1-DNA in peripheral blood mononuclear cells. Methods Mol Biol. 2014;1087:261-70. doi:10.1007/978-1-62703-670-2_21.

44. Durand CM, Ghiaur G, Siliciano JD, Rabi SA, Eisele EE, Salgado $\mathrm{M}$, et al. HIV-1 DNA is detected in bone marrow populations containing CD4+ T cells but is not found in purified CD34+ hematopoietic progenitor cells in most patients on antiretroviral therapy. $\mathrm{J}$ Infect Dis. 2012;205(6):1014-8. doi:10.1093/infdis/jir884.

45. Pauza CD, Trivedi P, McKechnie TS, Richman DD, Graziano FM. 2-LTR circular viral DNA as a marker for human immunodeficiency virus type 1 infection in vivo. Virology. 1994;205(2):470-8. doi: 10.1006/viro.1994.1667.

46. Sharkey M, Triques K, Kuritzkes DR, Stevenson M. In vivo evidence for instability of episomal human immunodeficiency virus type 1 cDNA. J Virol. 2005;79(8):5203-10. doi:10.1128/JVI.79.8. 5203-5210.2005.

47. Cohn LB, Silva IT, Oliveira TY, Rosales RA, Parrish EH, Learn $\mathrm{GH}$, et al. HIV-1 integration landscape during latent and active infection. Cell. 2015;160(3):420-32. doi:10.1016/j.cell.2015.01. 020.

48. O'Doherty U, Swiggard WJ, Jeyakumar D, McGain D, Malim MH. A sensitive, quantitative assay for human immunodeficiency virus type 1 integration. J Virol. 2002;76(21):10942-50.

49. Sanchez G, Xu X, Chermann JC, Hirsch I. Accumulation of defective viral genomes in peripheral blood mononuclear cells of human immunodeficiency virus type 1-infected individuals. J Virol. 1997;71(3):2233-40.

50. Yu JJ, Wu TL, Liszewski MK, Dai J, Swiggard WJ, Baytop C, et al. A more precise HIV integration assay designed to detect small differences finds lower levels of integrated DNA in HAART treated patients. Virology. 2008;379(1):78-86. doi:10.1016/j.virol.2008. 05.030.

51. Procopio FA, Fromentin R, Kulpa DA, Brehm JH, Bebin AG, Strain MC, et al. A novel assay to measure the magnitude of the 
inducible viral reservoir in HIV-infected individuals. EBioMed. 2015;2(8):872-81. doi:10.1016/j.ebiom.2015.06.019.

52. Duong YT, Qiu M, De AK, Jackson K, Dobbs T, Kim AA, et al. Detection of recent HIV-1 infection using a new limiting-antigen avidity assay: potential for HIV-1 incidence estimates and avidity maturation studies. PLoS One. 2012;7(3), e33328. doi:10.1371/ journal.pone.0033328.

53.• Henrich TJ, Hanhauser E, Marty FM, Sirignano MN, Keating S, Lee TH, et al. Antiretroviral-free HIV-1 remission and viral rebound after allogeneic stem cell transplantation: report of 2 cases. Ann Intern Med. 2014;161(5):319-27. doi:10.7326/M14-1027. This manuscript describes the comprehensive analysis of residual viremia in two individuals who underwent an allogeneic stem cell transplant in which no virus was found.

54.• Yukl SA, Boritz E, Busch M, Bentsen C, Chun TW, Douek D, et al. Challenges in detecting HIV persistence during potentially curative interventions: a study of the Berlin patient detects. PLoS Pathog. 2013;9(5):e1003347. doi:10.1371/journal.ppat.1003347. A comprehensive and collaborative analysis of the Berlin patient detects HIV; however, to date no viral rebound has been detected.

55. Burbelo PD, Bayat A, Rhodes CS, Hoh R, Martin JN, Fromentin R, et al. HIV antibody characterization as a method to quantify reservoir size during curative interventions. J Infect Dis. 2014;209(10): 1613-7. doi:10.1093/infdis/jit667.

56. Olesen R, Vigano S, Rasmussen TA, Sogaard OS, Ouyang Z, Buzon $\mathrm{M}$, et al. Innate immune activity correlates with CD4 T cell-associated HIV-1 DNA decline during latency-reversing treatment with panobinostat. J Virol. 2015;89(20):10176-89. doi:10. 1128/JVI.01484-15.

57. Hatano H, Jain V, Hunt PW, Lee TH, Sinclair E, Do TD, et al. Cellbased measures of viral persistence are associated with immune activation and programmed cell death protein 1 (PD-1)-expressing CD4+ T cells. J Infect Dis. 2013;208(1):50-6. doi:10.1093/infdis/ jis630.

58. Cockerham LR, Siliciano JD, Sinclair E, O'Doherty U, Palmer S, Yukl SA, et al. CD4+ and CD8+ T cell activation are associated with HIV DNA in resting CD4+ T cells. PLoS One. 2014;9(10), e110731. doi:10.1371/journal.pone.0110731.

59. This week's section. Science. 2015;349(6247):456-8. doi:10.1126/ science.349.6247.456

60. Kotler DP, Reka S, Borcich A, Cronin WJ. Detection, localization, and quantitation of HIV-associated antigens in intestinal biopsies from patients with HIV. Am J Pathol. 1991;139(4):823-30.
61. Chun TW, Nickle DC, Justement JS, Meyers JH, Roby G, Hallahan $\mathrm{CW}$, et al. Persistence of HIV in gut-associated lymphoid tissue despite long-term antiretroviral therapy. J Infect Dis. 2008;197(5): 714-20. doi:10.1086/527324.

62. Hatano H, Somsouk M, Sinclair E, Harvill K, Gilman L, Cohen M, et al. Comparison of HIV DNA and RNA in gut-associated lymphoid tissue of HIV-infected controllers and noncontrollers. Aids. 2013;27(14):2255-60. doi:10.1097/QAD.0b013e328362692f.

63. Yukl SA, Gianella S, Sinclair E, Epling L, Li Q, Duan L, et al. Differences in HIV burden and immune activation within the gut of HIV-positive patients receiving suppressive antiretroviral therapy. J Infect Dis. 2010;202(10):1553-61. doi:10.1086/656722.

64. Dahl V, Gisslen M, Hagberg L, Peterson J, Shao W, Spudich S, et al. An example of genetically distinct HIV type 1 variants in cerebrospinal fluid and plasma during suppressive therapy. J Infect Dis. 2014;209(10):1618-22. doi:10.1093/infdis/jit805.

65. Strategies for Management of Antiretroviral Therapy Study G, ElSadr WM, Lundgren J, Neaton JD, Gordin F, Abrams D, et al. CD4+ count-guided interruption of antiretroviral treatment. N Engl J Med. 2006;355(22):2283-96. doi:10.1056/NEJMoa062360.

66. Strategies for Management of Antiretroviral Therapy Study G, Lundgren JD, Babiker A, El-Sadr W, Emery S, Grund B, et al. Inferior clinical outcome of the CD4+ cell count-guided antiretroviral treatment interruption strategy in the SMART study: role of CD4+ Cell counts and HIV RNA levels during follow-up. J Infect Dis. 2008;197(8):1145-55. doi:10.1086/529523.

67. Pinkevych M, Cromer D, Tolstrup M, Grimm AJ, Cooper DA, Lewin SR, et al. HIV reactivation from latency after treatment interruption occurs on average every 5-8 days - implications for HIV remission. PLoS Pathog. 2015;11(7):e1005000. doi:10.1371/ journal.ppat.1005000. Modelling study that estimates that a 50-70-fold reduction in the reservoir may be required for a one-year ART remission.

68. Hill AL, Rosenbloom DI, Fu F, Nowak MA, Siliciano RF Predicting the outcomes of treatment to eradicate the latent reservoir for HIV-1. Proc Natl Acad Sci U S A. 2014;111(37):1347580. doi:10.1073/pnas.1406663111.

69.• Eriksson S, Graf EH, Dahl V, Strain MC, Yukl SA, Lysenko ES, et al. Comparative analysis of measures of viral reservoirs in HIV-1 eradication studies. PLoS Pathog. 2013;9(2):e1003174. doi:10. 1371/journal.ppat.1003174. A very thorough comparative analysis of measures of viral DNA and RNA compared to the viral outgrowth assay. 